\title{
PENGGUNAAN EKSTRAK BUAH ADAS DALAM MENGURANGI DISMENORE PADA REMAJA PUTRI
}

\author{
Hermayanti $^{1}$, Gita Kostania ${ }^{2}$, Siti Yulaikah ${ }^{3}$ \\ Poltekkes Kemenkes Surakarta Jurusan Kebidanan
}

\begin{abstract}
Background: According to the World Health Organization (WHO), adolescence is a transition period in which growth and development occur greatly improved both physically and psychologically. Dysmenorrhea is a complaint of teenage girl who often appear during menstruation. Dysmenore can be done pharmacologically and non pharmacologically. Exclusively by non pharmacological, one of them using herbal medicine by fennel fruit extract. This research tries to study the effectiveness of consuming fennel extract in reducing dysmenorrhea among teenage girls. Methods: The research method using quasy experimental design with the research design of two pretest-posttest design groups. The population is all teenage girls in SMPN 4 Mojosongo who take 116 female students. The sampling technique was purposive random sampling, using Slovin formula which obtained a sample of 54 respondents divided into two groups, each contains 27 respondents. Instrument test using Face Scale Rating Scale (FRS). Data analysis techniques that used are the Wilcoxon Signed Rank Test and the Mann-Whitney Test. Results: There was a significant decrease in dysmenorrhea both in the intervention group that was given fennel fruit extract (mean = $2.15 ; p=0.001<0.05$ ) and in the control group (average $=0.37 ; p=0.025<0.05$ ). The decrease that occurred in the control group was significantly greater in the control group ( $p=0.001<0.05)$. Conclusion: fennel fruit extract is effective in reducing dysmenorrhea in young women at SMPN 4 Mojosongo, Boyolali Regency.
\end{abstract}

Keywords: Fennel Fruit Extract, Dysmenorrhea, Teenage Girls

\section{PENDAHULUAN}

Menurut World Health

Organization (WHO), masa remaja adalah suatu periode transisi yang memiliki rentang dari masa kanak-kanak yang bebas dari tanggung jawab sampai pencapaian tanggung jawab pada masa remaja. Pertumbuhan dan perkembangan pada masa remaja sangat pesat, baik fisik maupun psikologis (Hurlock, 2009; Proverawati \& Misaroh,2009).

Remaja putri pada masa pubertas ditandai dengan terjadinya menstruasi. Menstruasi adalah pengeluaran darah secara periodik dan sel-sel tubuh dari vagina yang berasal dari dinding rahim wanita. Biasanya menstruasi dimulai pada usia 10 sampai 16 tahun, tergantung pada beberapa faktor antara lain kesehatan wanita, status nutrisi dan berat tubuh yang proporsional. Menstruasi berlangsung kira- kira sekali sebulan sampai wanita mencapai usia 45-50 tahun (Kinanti,2009). Keluhan-keluhan yang sering muncul pada saat menstruasi adalah mudah tersinggung, gelisah, sukar tidur, gangguan konsentrasi, payudara mengalami pembesaran dan gangguan yang berkenaan dengan masa haid berupa dismenore (Manuaba, 2009). Hal ini 
sejalan dengan penelitian Omvidvar di Amerika Serikat bahwa dysmenorrhea mengakibatkan $23,6 \%$ dari penderitanya tidak masuk sekolah (Sophia, 2013). Sedangkan dalam penelitian Klein dan Litt di Amerika, melaporkan bahwa prevalensi dismenore 59,7\%, dengan nyeri menstruasi berat sebanyak $12 \%$, nyeri sedang $37 \%$ dan nyeri ringan $49 \%$ (Anurogo, 2011).

\section{Dysmenorhea}

dikategorikan

menjadi dua yaitu (1) dismenore primer berkaitan dengan nyeri menstruasi yang terjadi tanpa terdapat kelainan anatomis alat kelamin, sedangkan (2) dysmenorrhea sekunder yaitu nyeri menstruasi yang berhubungan dengan kelainan anatomis yang jelas atau masalah patologis di rongga panggul (Manuaba, 2010). Prevalensi dysmenorhea di Indonesia sebesar $64,25 \%$ yang terdiri dari $54,89 \%$ dismenore primer dan $9,36 \%$ dismenore sekunder (Santoso, 2008). Dismenore dapat dikurangi secara farmakologis dan non farmakologis. Secara farmakologis dapat dikurangi dengan obat golongan NSAIDs (Non Steroid Anti-Inflamatory Drugs) diantaranya ibuprofen, diclofenac, acetaminophen tetapi obat-obat tersebut menyebabkan ketergantungan dan memiliki kontra indikasi yaitu hipersensitivitas, ulcus peptic (tukak lambung), perdarahan atau perforasi gastrointestinal, insufisiensi ginjal dan resiko tinggi perdarahan (Ningsih, 2011). Sedangkan secara non farmakologis antara lain dengan pengaturan posisi, teknik relaksasi, manajemen sentuhan, manajemen lingkungan, distraksi, imajinasi, kompres dan pemberian obat herbal. Salah satu obat herbal yang dapat digunakan untuk mengatasi dysmenorhea yaitu ekstrak buah adas (Foeniculum vulgare Mill) (Hariana, 2009).

Adas (Foeniculum vulgare Mill) merupakan salah satu dari berbagai tanaman obat yang dianggap bermanfaat bagi kesehatan. Adas (Foeniculum vulgare Mill) mengandung trans-anethol, fenchone dan estragol yang diduga memiliki potensi sebagai fitoestrogen (Agustini dan Saepudin, 2007). Adas dapat dimanfaatkan untuk mengatasi sakit perut, mual, perut kembung, muntah, diare, nyeri haid, dan haid tidak teratur (Hartini et al, 2009).

Dari hasil penelitian yang dilakukan oleh Shabnam Omidvar, Sedighe Esmailzadeh, Mahmod Baradaran dan Zahra Basirat (2012) pada 60 remaja putri dengan dysmenorrhea, dimana 50 kasus selesai menjalani pengobatan dan perawatan selama dua siklus dibagi dalam dua kelompok (studi dan plasebo). Dalam kelompok studi diberikan sebuah kapsul 30 mg ekstrak adas, empat kali sehari selama tiga hari sejak awal periode menstruasi dan pada kelompok plasebo diberikan kapsul yang mengandung tepung terigu dengan dosis yang sama. Didapatkan hasil bahwa kelompok studi menunjukkan hasil yang lebih efektif daripada plasebo dalam menghilangkan nyeri selama menstruasi.

Subjek penelitian ini adalah remaja putri SMPN 4 Mojosongo yang berjumlah 116 siswi. Berdasarkan studi pendahuluan yang dilakukan peneliti dari 110 siswi, didapatkan data bahwa 80 siswi diantaranya mempunyai riwayat dysmenorrhea, dimana 35 siswi mengalami nyeri ringan, 34 siswi nyeri sedang dan 11 siswi nyeri berat. Penanganan yang telah dilakukan untuk mengurangi atau menghilangkan dysmenorhea antara lain dengan obat analgesik sebanyak 24 siswi, dibiarkan 
saja sebanyak 37 siswi, istirahat atau tidur sebanyak 16 siswi dan menangis sebanyak 3siswi.

Penelitian ini bertujuan untuk mengetahui efektifitas mengonsumsi ekstrak buah ada dalam mengurangi dismenore pada remaja putri di SMPN 4 Mojosongo Kabupaten Boyolali.

\section{METODE PENELITIAN}

Penelitian termasuk jenis studi kuantitatif yang dilakukan dalam bentuk quasy experiment dengan rancangan two groups pretest-posttest design. Populasi adalah seluruh remaja putri di SMPN 4 Mojosongo Kabupaten Boyolali yang berjumlah 116 siswi. Sampel sebanyak 54 siswi (dihitung menurut rumus Slovin) diambil dengan teknik purposive random sampling. Sampel dibagi ke dalam dua kelompok dengan jumlah yang sama, yaitu kelompok intervensi (mengonsumsi ekstrak buah adas) dan kelompok kontrol, masing-masing sebanyak 27 responden.

Variabel bebas adalah perlakuan baik mengonsumsi ekstrak buah adas atau tidak (mengonsumsi placebo). Variabel terikat adalah dysmenorrhea yang diukur sebanyak dua kali pada tiap kelompok yaitu pada bulan pertama eksperimen (sebelum perlakuan) dan pada bulan kedua eksperimen (sesudah perlakuan). dysmenorrhea diukur dengan Face Rating Scale (FRS) dengan rentang skor 0-10.

Berbagai karakteristik seperti umur, status gizi, dan penghasilan orang tua, dideskripsikan dalam bentuk distribusi frekuensi. dysmenorrhea dideskripsikan dengan beberapa parameter statistik seperti mean, standar deviasi, median, minimum, dan maksimum. Uji normalitas skor dysmenorhea dilakukan dengan kolmogorov-smirnov test.

Uji beda dysmenorrhea antara sebelum dan sesudah perlakuan dilakukan dengan paired samples $t$ test atau wilcoxon signed rank test. Uji beda perubahan dismenore antara kedua kelompok eksperimen dilakukan dengan independent samples $t$ test atau mannwhitney test. Taraf signifikansi yang digunakan adalah 5\%. Semua prosedur pengolahan data dilakukan dengan software SPSS for Windows 20.

\section{HASIL PENELITIAN}

1. Deskripsi Karakteristik

Deskripsi karakteristik berupa umur, status gizi, dan tingkat ekonomi (penghasilan orang tua), dapat dilihat pada tabel 1 .

Tabel 1. Deskripsi Karakteristik

\begin{tabular}{lrrrr}
\hline \multirow{2}{*}{ Karakteristik } & \multicolumn{3}{c}{ Intervensi } & \multicolumn{2}{c}{ Kontrol } \\
& f & \% & f & \% \\
\hline Umur & & & & \\
\hline 12 tahun & 4 & 14,8 & 3 & 11,1 \\
13 tahun & 11 & 40,7 & 13 & 48,1 \\
14 tahun & 9 & 33,3 & 7 & 25,9 \\
15 tahun & 3 & 11,1 & 4 & 14,8 \\
\hline Status Gizi & & & & \\
\hline Kurang & 2 & 7,4 & 1 & 3,7 \\
Normal & 20 & 74,1 & 22 & 81,5 \\
Lebih & 5 & 18,5 & 4 & 14,8 \\
\hline Penghasian
\end{tabular}

\begin{tabular}{lrlrl}
\hline $\begin{array}{l}\text { Penghasilan } \\
\text { Ortu }\end{array}$ & & & & \\
\hline$<1,2$ juta & 7 & 25,9 & 4 & 14,8 \\
$1,2-2,5$ juta & 17 & 63,0 & 20 & 74,1 \\
$>2,5$ juta & 3 & 11,1 & 3 & 11,1 \\
\hline Total & $\mathbf{2 7}$ & $\mathbf{1 0 0}$ & $\mathbf{2 7}$ & $\mathbf{1 0 0}$ \\
\hline
\end{tabular}

Berdasarkan tabel 1 diketahui bahwa distribusi responden menurut umur, status gizi, dan penghasilan orang tua, relatif berimbang di antara kedua kelompok. Baik pada kelompok intervensi maupun pada kelompok kontrol, sebagian besar responden merupakan siswi berumur 13 tahun, memiliki status gizi normal, dan memiliki orang tua 
berpenghasilan 1,2 hingga 2,5 juta.

2. Deskripsi Dysmenorrhea Remaja Putri Pada Kelompok Intervensi

Deskripsi skor dysmenorhea kelompok intervensi pada bulan pertama, bulan kedua, dan selisihnya, dapat dilihat pada table 2 .

Tabel 2. Deskripsi Dysmenorrhea Remaja Putri pada Kelompok Intervensi

\begin{tabular}{lrrrr}
\hline Nilai & \multicolumn{3}{c}{ Skor Dismenore } & \\
\cline { 2 - 4 } Statistik & Bln I & Bln II & Selisih & p \\
\hline Mean & 5,48 & 3,33 & 2,15 & \\
SD & 1,312 & 1,840 & 1,350 & \\
Median & 6 & 4 & 2 & 0,001 \\
Min & 4 & 0 & 0 & \\
Maks & 8 & 6 & 4 & \\
\hline
\end{tabular}

\begin{tabular}{ccccc}
$\begin{array}{c}\mathbf{p} \\
\text { (normalitas) }\end{array}$ & $\mathbf{0 , 0 0 1}$ & $\mathbf{0 , 0 0 1}$ & $\mathbf{0 , 0 0 1}$ & \\
\hline Berdasarkan & tabel 2 & dapat
\end{tabular} dilihat bahwa pada bulan pertama, responden kelompok intervensi memiliki mean skor dysmenorrhea sebesar 5,48 yang berarti bahwa rata-rata responden mengalami dysmenorrhea sedang. Uji normalitas dengan kolmogorovsmirnov test untuk data skor dismenore bulan pertama menghasilkan nilai p sebesar 0,001 . Oleh karena $\mathrm{p}<0,05$ maka data skor dysmenorrhea bulan pertama kelompok intervensi dinyatakan tidak berdistribusi normal.

Pada bulan kedua, responden kelompok intervensi memiliki mean skor dysmenorhea sebesar 3,33 yang berarti bahwa rata-rata responden mengalami dysmenorhea ringan.

Sedangkan pada Uji normalitas dengan kolmogorov-smirnov test untuk data skor dysmenorhea bulan kedua menghasilkan nilai $\mathrm{p}$ sebesar 0,001 . Oleh karena $\mathrm{p}<0,05$ maka data skor dysmenorrhea bulan kedua kelompok intervensi dinyatakan tidak berdistribusi normal.

Terjadi penurunan skor dysmenorhea dari bulan pertama ke bulan kedua. Uji normalitas dengan kolmogorov-smirnov test untuk data selisih skor dysmenorhea bulan pertama dan kedua menghasilkan nilai $\mathrm{p}$ sebesar 0,001 . Oleh karena $p<0,05$ maka data selisih skor dysmenorhea bulan pertama dan kedua kelompok intervensi dinyatakan tidak berdistribusi normal.

Uji beda skor dysmenorrhea antara bulan pertama dan kedua dilakukan dengan teknik non parametrik yaitu wilcoxon signed rank test. Pengujian menghasilkan nilai $\mathrm{p}$ sebesar 0,000 . Nilai $\mathrm{p}<0,05$ berarti bahwa ada perbedaan skor dysmenorhea yang signifikan antara bulan pertama dan kedua. Dengan demikian diketahui bahwa pada responden kelompok intervensi (mengonsumsi ekstrak buah adas) terjadi penurunan dysmenorhea.

3. Deskripsi Dysmenorrhea Remaja Putri pada Kelompok Kontrol

Deskripsi skor dysmenorrhea kelompok kontrol pada bulan pertama, bulan kedua, dan selisihnya, dapat dilihat pada table 3 .

Tabel 3. Deskripsi Dysmenorrhea Remaja Putri pada Kelompok Kontrol

\begin{tabular}{|c|c|c|c|c|}
\hline \multirow{2}{*}{$\begin{array}{l}\text { Nilai } \\
\text { Statistik }\end{array}$} & \multicolumn{3}{|c|}{ Skor Dismenore } & \multirow[b]{2}{*}{$\mathbf{p}$} \\
\hline & Bln I & BIn II & Selisih & \\
\hline Mean & 5,56 & 5,19 & 0,37 & \\
\hline SD & 1,155 & 1,145 & 0,792 & \\
\hline Median & 6 & 6 & 0 & 0,025 \\
\hline Min & 4 & 4 & 0 & \\
\hline Maks & 8 & 8 & 2 & \\
\hline $\begin{array}{c}\mathbf{p} \\
\text { (normalitas) }\end{array}$ & $\mathbf{0 , 0 0 1}$ & $\mathbf{0 , 0 0 1}$ & 0,001 & \\
\hline
\end{tabular}

Berdasarkan tabel 3 dapat dilihat bahwa pada bulan pertama, responden 
kelompok kontrol memiliki mean skor dysmenorrhea sebesar 5,56 yang berarti bahwa rata-rata responden mengalami dismenore sedang. Uji normalitas dengan kolmogorov-smirnov test untuk data skor dismenore bulan pertama menghasilkan nilai $\mathrm{p}$ sebesar 0,001 . Oleh karena $p<0,05$ maka data skor dysmenorrhea e bulan pertama kelompok kontrol dinyatakan tidak berdistribusi normal.

Pada bulan kedua, responden kelompok kontrol memiliki mean skor dysmenorrhea sebesar 5,19 yang berarti bahwa rata-rata responden mengalami dysmenorrhea sedang. Uji normalitas dengan kolmogorov-smirnov test untuk data skor dismenore bulan kedua menghasilkan nilai $\mathrm{p}$ sebesar 0,001 . Oleh karena $\mathrm{p}<0,05$ maka data skor dysmenorrhea bulan kedua kelompok kontrol dinyatakan tidak berdistribusi normal.

Terjadi penurunan skor dysmenorrhea dari bulan pertama ke bulan kedua. Uji normalitas dengan kolmogorov-smirnov test untuk data selisih skor dismenore bulan pertama dan kedua menghasilkan nilai $\mathrm{p}$ sebesar 0,001 . Oleh karena $p<0,05$ maka data selisih skor dysmenorrhea bulan pertama dan kedua kelompok kontrol dinyatakan tidak berdistribusi normal.

Uji beda skor dysmenorrhea antara bulan pertama dan kedua dilakukan dengan teknik non parametrik yaitu wilcoxon signed rank test. Pengujian menghasilkan nilai p sebesar 0,025 . Nilai $\mathrm{p}<0,05$ berarti bahwa ada perbedaan skor dysmenorhea yang signifikan antara bulan pertama dan kedua. Dengan demikian diketahui bahwa pada responden kelompok kontrol (tidak mengonsumsi ekstrak buah adas) terjadi penurunan dysmenorrhea.

4. Uji Beda Penurunan Dysmenorrhea Remaja Putri Antara Kelompok Intervensi Dengan Kelompok Kontrol Deskripsi selisih skor dysmenorhea dan uji beda antara kedua kelompok, dapat dilihat pada tabel 4.

Tabel 4. Uji Beda Penurunan dysmenorhea Remaja Putri antara Kelompok Intervensi dengan Kelompok Kontrol

\begin{tabular}{lrrr}
\hline \multirow{2}{*}{$\begin{array}{l}\text { Nilai } \\
\text { Statistik }\end{array}$} & \multicolumn{2}{c}{$\begin{array}{c}\text { Selisih Skor } \\
\text { dysmenorhea }\end{array}$} & \multirow{2}{*}{$\mathbf{p}$} \\
\cline { 2 - 3 } & Intervensi & Kontrol & \\
\hline Mean & 2,15 & 0,37 & \\
SD & 1,350 & 0,792 & \\
Median & 2 & 0 & 0,001 \\
Min & 0 & 0 & \\
Maks & 4 & 2 & \\
\hline \multicolumn{1}{c}{$\mathbf{p}$} & $\mathbf{0 , 0 0 1}$ & $\mathbf{0 , 0 0 1}$ & \\
(normalitas) & & & \\
\hline
\end{tabular}

Berdasarkan tabel 4 dapat dilihat bahwa penurunan skor dysmenorhea kelompok intervensi memiliki mean sebesar 2,15 sedangkan penurunan skor dismenore kelompok kontrol memiliki mean sebesar 0,37. Uji normalitas dengan kolmogorovsmirnov test untuk data selisih skor dysmenorhea pada kedua kelompok menghasilkan nilai $\mathrm{p}$ masing- masing sebesar 0,001 . Oleh karena $\mathrm{p}<0,05$ maka data selisih skor dysmenorhea kedua kelompok dinyatakan tidak berdistribusi normal.

Berdasarkan nilai mean (ratarata) dan median (nilai tengah), secara deskriptif terlihat bahwa penurunan dysmenorhea yang terjadi pada responden kelompok intervensi lebih besar dibandingkan pada responden kelompok kontrol. Uji beda antara kedua kelompok dengan teknik non parametrik mann-whitney test 
menghasilkan nilaip sebesar 0,001 .

Nilai $\mathrm{p}<0,05$ berarti bahwa ada perbedaan selisih skor yang signifikan antara kedua kelompok. Dengan demikian diketahui bahwa terdapat perbedaan penurunan dismenore antara kelompok intervensi dan kelompok kontrol. Hal ini membuktikan kebenaran hipotesis penelitian yaitu mengonsumsi ekstrak buah adas efektif dalam mengurangi dismenore pada remaja putri di SMPN 4 Mojosongo Kabupaten Boyolali.

\section{PEMBAHASAN}

Hasil penelitian menunjukkan bahwa pemberian ekstrak buah adas efektif dalam mengurangi dismenore pada remaja putri di SMPN 4 Mojosongo Kabupaten Boyolali. Ini sesuai dengan teori yang dikemukakan oleh Hariana (2009) bahwa ekstrak buah adas mengandung agen anti spasmodik yang berfungsi menghambat pengeluaran enzim fosfolipase sehingga dapat mengurangi terbentuknya PGE2 dan PGF2 alfa yang menyebabkan terjadinya dysmenorhea. Selain itu ekstrak buah adas juga mengandung anethol yang memberikan efek analgesik dimana anethol di sini bergabung dengan reseptor dopamin tubuh untuk menekan sensitasi ujung saraf aferen nervus pelvicus sehingga rasa sakit dapatberkurang.

Hasil penelitian ini juga didukung hasil penelitian yang dilakukan oleh Omidvar (2012) yang menyatakan bahwa ekstrak buah adas (Foeniculum vulgare mill) merupakan obat herbal yang efektif untuk dysmenorhea. Dosis yang digunakan adalah $30 \mathrm{mg}$ ekstrak buah adas dalam tiap kapsul diminum empat kali sehari selama dua hari sejak mulai menstruasi.

Hasil penelitian pada kelompok intervensi menunjukkan bahwa responden mengalami penurunan dismenore dengan adanya pemberian ekstrak buah adas dari kategori sedang menjadi ringan. Deskripsi tersebut sesuai dengan teori yang dikemukakan oleh Yuliarti (2009) bahwa istilah dismenore hanya dipakai jika nyeri saat menstruasi (yang umumnya berupa kram dan terpusat di bagian perut bawah) terjadi demikian hebatnya, oleh karena hampir semua wanita mengalami rasa tidak enak di perut bagian bawah sebelum dan selama menstruasi. Dikatakan demikian apabila nyeri yang terjadi ini memaksa penderita untuk beristirahat dan meninggalkan aktivitasnya untuk beberapa jam atau hari. Manuaba (2007) menyatakan bahwa gambaran dari dysmenorhea sedang adalah merespon nyeri dengan merintih dan menekannekan bagian yang nyeri, diperlukan obat penghilang rasa nyeri tanpa perlu meninggalkankerja.

Hasil penelitian pada kelompok kontrol menunjukkan bahwa responden mengalami penurunan dysmenorhea dismenore meski tanpa mengonsumsi ekstrak buah adas. Remaja putri yang tidak mengonsumsi ekstrak buah adas memang mengalami penurunan dysmenorhea namun pada dasarnya tingkat dysmenorhea yang mereka rasakan tetap sama yaitu sedang. Dismenore yang terjadi secara berulang dari bulan ke bulan menunjukkan bahwa nyeri yang dirasakan tersebut termasuk nyeri kronis. Hal ini sebagaimana yang dikemukakan oleh Muttaqin (2008) bahwa nyeri kronis merupakan suatu keadaan yang berlangsung secara konstan atau intermiten dan menetap sepanjang satu periode waktu. Oleh karena terjadi berulang-ulang maka persepsi sensorik 
(perasaan subyektif) terus-menerus beradaptasi sehingga penderita mulai terbiasa dengan rasa nyeri yang dialami dan secara subyektif menganggap bahwa nyeri tersebut terus berkurang seiring waktu. Inilah salah satu alasan kenapa remaja putri yang tidak diberi ekstrak buah adas pun tetap mengalami penurunan dysmenorhea.

Penanganan

dysmenorhea

merupakan aspek pelayanan kesehatan reproduksi oleh bidan. Pemberian layanan terapi komplementer oleh bidan masih sangat minim (14,4\%) (Kostania, 2015). Dengan hasil penelitian ini, diharapkan dapat menjadi khasanah keilmuan untuk meningkatkan penggunaan terapi komplementer dalam layanan kebidanan dengan memanfaatkan bahan bahan yang berasal dari alam.

\section{KESIMPULAN DAN SARAN}

Kesimpulan

Penggunaan ekstrak buah adas efektif dalam mengurangi dismenore pada remaja putri. Penggunaan ekstrak buah adas dengan cara dikonsumsi oleh remaja putri yang sedang menstruasi dan mengalami dysmenorhea.

Saran

1. Bagi instansi kesehatan (Puskesmas) untuk menambah informasi mengenai konsumsi ekstrak buah adas sebagai alternatif cara mengurangi dysmenorhea dalam penyuluhan kesehatan yang dilakukan secara periodik di sekolah- sekolah.

2. Bagi remaja putri tentu disarankan untuk melakukan alternatif tersebut untuk mengurangi dysmenorhea yang dialaminya.

3. Untuk penelitian selanjutnya disarankan agar melibatkan subyek dengan cakupan usia yang lebih luas. Sangat disarankan juga untuk melakukan eksperimen dengan membandingkan beberapa teknik non farmakologis.

\section{DAFTAR RUJUKAN}

Agustini, K., Saepuddin, Y., 2007, Pengaruh Ekstrak Buah Adas (Foeniculum Vulgare Mill) Terhadap Kadar Hormon Estradiol dan FSH Plasma Tikus Putih Betina Galur Wistar Yang Diovariektomi. Artocarpus http:\isjd.pdii.lipi.go.idindex.php\ Search.html. Diunduh 25 Agustus 2013

Anurogo, Dito, 2011, Segala Sesuatu tentang Nyeri Haid http: \www.kabarindonesia.com/be rita.php? pil $=3 \& d n=20080619164$ 804. Diakses 185 Agustus 2017 pukul 17.18 WIB.

Hariana, A, 2009, Tumbuhan Obat dan Khasiatnya, Swadaya, Depok.

Hartini, et al, 2009, Daya Anti Bakteri Campuran Ekstrak Etanol Buah Adas (Foeniculum Vulgare Mill) dan Kulit Batang Pulasari (alyxia reinwardtii IBL), Fakultas Farmasi Universitas Sanata Dharma Yogyakarta dan Fakultas Farmasi Universitas Gadjah Mada Yogyakarta.

Hurlock, Elizabeth, B, 2009, Psikologi Perkembangan Suatu Pendekatan Sepanjang Rentang Kehidupan Edisi Kelima, Erlangga, Jakarta.

Kinanti, 2009, Rahasia Pintar Wanita, Aulya Publishing, Yogyakarta.

Kostania, G. 2015. Pelaksanaan Pelayanan Kebidanan Komplementer Pada Bidan Praktek 
Mandiri di Kabupaten Klaten. Gaster: Jurnal Kesehatan, 12(1), 46-72.

Manuaba, Ida Ayu Chandranita, 2009, Memahami Kesehatan Reproduksi Wanita, EGC, Jakarta.

Muttaqin, Arif, 2008, Buku Ajar Asuhan Keperawatan Klien dengan Gangguan Sistem Persarafan, Salemba Medika, Jakarta.

Ningsih, Ratna, 2011, Efektifitas Paket Pereda Terhadap Intensitas Nyeri pada Remaja dengan Dismenore di SMAN Kecamatan Curug, Tesis, Universitas Indonesia.

Omidvar, S., Esmailzadeh, S., Baradaran, M., and Basirat, Z., 2012, Effect Of Fennel On Pain Intensity In Dysmenorrhoea: A Placebo-Controlled Trial, 33(2): 311-313.

Proverawati, Atikah dan Misaroh Siti, 2009, Menarche Menstruasi Pertama Penuh Makna, Nuha Medika, Yoogyakarta.

Santoso, 2008, Angka Kejadian Nyeri Haid pada Remaja Indonesia, Journal of Obstetri Gynecology.

Sophia, Frenita dkk, 2012, FaktorFaktor yang Berhubungan Dengan Dysmenorrhoea Siswi SMKN 10 Medan Tahun 2013, Mahasiswa Departemen Epidemiologi, FKM USU

Yuliarti, 2009, Hidup Sehat dengan Sayuran, Cakrawala, Yogyakarta 